\title{
Editorial
}

\section{High Blood Pressure prevention and control: from evidence to action}

\author{
Presión arterial elevada: de la evidencia a la acción
}

\section{Lena Barrera}

Control and Prevention of Chronic Diseases research group. Departamento de Medicina Interna, Facultad de Salud, Universidad del Valle. Cali, Colombia

Barrera L. High Blood Pressure prevention and control: from evidence to action. Colomb Med (Cali). 2018; 49(2): 137-8. doi:10.25100/cm.v49i2.3940.

(C) 2018. Universidad del Valle. This is an Open Access article distributed under the terms of the Creative Commons Attribution License, which permits unrestricted use, distribution, and reproduction in any medium, provided the original author and source are credited.

The Pan American Health Organization (PAHO) with the World Hypertension League has established the $17^{\text {th }}$ May to promote the prevention and control of High Blood Pressure (HBP) ${ }^{1}$. Currently nearly 1.13 billion of adults suffer from HBP (blood pressure $\geq 140 / 90 \mathrm{~mm} \mathrm{Hg}$ ) worldwide ${ }^{2}$. While HBP prevalence decreased in high income countries (HIC) between 1975 and 2015, the opposite trend was observed in low- and middleincome countries (LMIC) $)^{3}$. Particularly, in Latin American and Caribbean countries the prevalence decreased from $40.6 \%$ to $26.8 \%$ and from $26.8 \%$ to $19.4 \%$ for men and women between 45 to 49 years old respectively ${ }^{3}$. However, in 2015, HBP accounted for 8.9 of the total of disability adjusted life years (DALYS) and was associated with 4.9 million, 2.0 million and 1.5 million deaths due to ischemic heart disease, hemorrhagic stroke and ischemic stroke respectively ${ }^{4}$. Therefore, HBP is the leading cardiovascular risk factor worldwide. In Colombia, the last National Health Survey reported a global prevalence of $22.8 \%$ and nearly $60 \%$ for those between 60 and 69 years in $2007^{5}$.

High Blood Pressure have been clearly associated with biological risk factors and environment conditions. Studies carried out in western societies have revealed that whereas systolic blood pressure rises continually with age starting at 30 years; diastolic blood pressure rises continually until 50 years and then remains stable or slightly decreases ${ }^{6}$. High Blood Pressure has been found positively associated with parental high blood pressure, pre-eclampsia, low birth and increases in body mass index ${ }^{7}$. While increased physical activity and low salt consumption have been found negatively correlated with $\mathrm{HBP}^{7}$. At macro level, urbanization and pollution has been linked to higher prevalence of $\mathrm{HBP}^{8,9}$. Lower socio-economic status and lower education have been reported associated with higher prevalence of HBP, mainly in HICs although little evidence has been documented in LMICs ${ }^{10,11}$. Generally, people living in rural areas working in agriculture and manual activities have lower blood pressure ${ }^{12}$.
High Blood Pressure and related cardiovascular diseases are preventable and interventions at both population and individual level have effectively reduced the burden of $\mathrm{HBP}^{7}$. Government regulations to lower salt content added to processed food is one the most supported population interventions ${ }^{13}$. A decline of $30 \%$ in sodium intake has been associated with a reduction of 10 $\mathrm{mm} \mathrm{Hg}$ in the average population of systolic and diastolic blood pressure $^{14}$. At individual level the use of pharmacological and non-pharmacological interventions has clearly demonstrated the benefits of lowering BP. Randomized controlled trials have shown that a reduction of $10 \mathrm{~mm} \mathrm{Hg} \mathrm{BP} \mathrm{in} \mathrm{systolic} \mathrm{blood} \mathrm{pressure} \mathrm{results}$ in $17 \%$ and $27 \%$ lower probability of suffering from coronary heart disease and stroke respectively ${ }^{15}$. Increased physical activity, low salt intake, loss weight, moderate alcohol consumption and the DASH or Meditarrean diets decrease systolic blood pressure by $6.0 \mathrm{~mm} \mathrm{Hg}$ on average ${ }^{16}$.

In spite of having ample evidence on the effectiveness of prevention and treatment for HBP, only $50 \%$ of hypertensive people have BP controlled (BP $<140 / 90 \mathrm{~mm} \mathrm{Hg}$ ) worldwide ${ }^{17}$. Whereas in 2010, the HIC rates of awareness, treatment and control were $67.0 \%$ $55.6 \%, 50.4 \%$ respectively, the equivalent in LMIC rates were $37.9 \%, 29.0 \%$ and $26.3 \%{ }^{17}$. Similar results have been provided by the PURE study which included population from Latin American countries. In Colombia, by example, the PURE study showed 51.9\% awareness of HBP, $77.5 \%$ were on antihypertensive treatment and $37.1 \%$ had HBP controlled ${ }^{18}$.

Tackling the burden of HBP is a complex public health issue. A comprehensive and life course approach is needed to impact the multifactorial factors that accounting for the prevalence, access to treatment and the control of $\mathrm{HBP}^{7,19}$. The approach should include an adequate pregnancy care, the promotion of healthy behaviors for all population such as low salt intake, physical activity, weight loss and moderate alcohol consumption, the early detection of 
increases in BP, universal access to pharmacological and nonpharmacological interventions and the monitoring of HBP. To accomplish the objectives the health sector needs to work with other social sectors such as the educational, food makers and social media as well.

We celebrate the "Know your numbers" 2018 PAHO initiative to improve the control and prevention of $\mathrm{HBP}^{1}$. Each adult should be prompted to know his BP level. Standardized accurate measurement of BP should be available for all population. Health workers need to be trained on the method of measurement BP. Health services also could monitor the numbers of adults that have been checked BP among those for whom health care has been provided. Having BP measured, people should be encouraged to adapt healthy behavior to prevent increases in blood pressure levels and HPB related diseases. Certainly, the measurement of BP will lead to increases in the rate of HBP awareness and so knowing the roots of the HBP burden.

Conflict of interest:

I have no conflicts of interest to declare

\section{References}

1. Panamercian Health Organization. World Hypertension Day 2018: Know your numbers 2018. Accessed: 03 May 2018. Available from: https://www.paho.org/hq/index.php?option=com conten $\underline{\mathrm{t} \& v i e w=\text { article\&id }=14300 \% 3 \mathrm{Adia}-\text { mundial-de-la-hipertension- }}$ 2018-conoce-tus-numeros\&catid=9283\%3Aworld-hypertensionday\&Itemid $=72266 \% \mathrm{E} 2 \% 8 \mathrm{C} \% \mathrm{~A} 9=\mathrm{en} \& \mathrm{lang}=\mathrm{en}$.

2. World Health Organization. Global Health Observatory (GHO) Data. Blood pressure. 2018. Available from: http://www.who.int/ gho/ncd/risk factors/blood pressure prevalence/en/.

3. NCD Risk Factor Collaboration (NCD-RisC). Worldwide trends in blood pressure from 1975 to 2015: a pooled analysis of 1479 population-based measurement studies with 19.1 million participants. Lancet. 2017;389(10064):37-55. doi: 10.1016/S01406736(16)31919-5.

4. Forouzanfar MH, Liu P, Roth GA, Ng M, Biryukov S, Marczak L, et al. Global burden of hypertension and systolic blood pressure of at least 110 to $115 \mathrm{~mm} \mathrm{hg,} \mathrm{1990-2015.} \mathrm{JAMA.} \mathrm{2017;317(2):165-82.}$

5. Ministerio de la Protección Social. Encuesta Nacional de Salud 2007. Resultados nacionales. Bogota; 2007. Available from: https:// www.minsalud.gov.co/Documentos $\% 20 y \% 20$ Publicaciones/ ENCUESTA\%20NACIONAL.pdf.

6. Franklin SS, Gustin WT, Wong ND, Larson MG, Weber MA, Kannel WB, et al. Hemodynamic patterns of age-related changes in blood pressure. The Framingham Heart Study. Circulation. 1997;96(1):308-15.

7. Olsen MH, Angell SY, Asma S, Boutouyrie P, Burger D, Chirinos JA, et al. A call to action and a lifecourse strategy to address the global burden of raised blood pressure on current and future generations: the \&lt;em\&gt;Lancet\&lt;/em\&gt; Commission on hypertension. Lancet. 2016; 388(10060):2665-712.
8. Liu C, Chen R, Zhao Y, Ma Z, Bi J, Liu Y, et al. Associations between ambient fine particulate air pollution and hypertension: A nationwide cross-sectional study in China. Sci Total Environm. 2017; 584-585:869-74.

9. Danaei G, Singh GM, Paciorek CJ, Lin JK, Cowan MJ, Finucane $\mathrm{MM}$, et al. The global cardiovascular risk transition: associations of four metabolic risk factors with national income, urbanization, and Western diet in 1980 and 2008. Circulation. 2013;127(14):1493502. doi: 10.1161/CIRCULATIONAHA.113.001470.

10. Lucumi DI, Schulz AJ, Roux AVD, Grogan-Kaylor A. Income inequality and high blood pressure in Colombia: a multilevel analysis. Cad Saude Publica. 2017;33(11): e00172316.

11. Leng B, Jin Y, Li G, Chen L, Jin N. Socioeconomic status and hypertension: a meta-analysis. J Hypertens. 2015;33(2):221-9.

12. Busingye D, Arabshahi S, Subasinghe AK, Evans RG, Riddell MA, Thrift AG. Do the socioeconomic and hypertension gradients in rural populations of low- and middle-income countries differ by geographical region? A systematic review and meta-analysis. Internat J Epidemiol. 2014; 43(5):1563-77.

13. He FJ, Pombo-Rodrigues S, MacGregor GA. Salt reduction in England from 2003 to 2011: its relationship to blood pressure, stroke and ischaemic heart disease mortality. BMJ Open. 2014;4(4): e004549. doi: 10.1136/bmjopen-2013-004549.

14. Karppanen H, Mervaala E. Sodium intake and hypertension. Prog Cardiovasc Dis. 2006;49(2):59-75.

15. Ettehad D, Emdin CA, Kiran A, Anderson SG, Callender $\mathrm{T}$, Emberson J, et al. Blood pressure lowering for prevention of cardiovascular disease and death: a systematic review and metaanalysis. Lancet. 2016; 387(10022):957-67.

16. Vamvakis A, Gkaliagkousi E, Triantafyllou A, Gavriilaki E, Douma S. Beneficial effects of nonpharmacological interventions in the management of essential hypertension. JRSM Cardiovasc Dis. 2017; 6: 2048004016683891.

17. Mills KT, Bundy JD, Kelly TN, Reed JE, Kearney PM, Reynolds $\mathrm{K}$, et al. Global Disparities of Hypertension Prevalence and Control. Circulation. 2016;134(6):441.

18. Camacho PA, Gomez-Arbelaez D, Molina DI, Sanchez G, Arcos E, Narvaez C, et al. Social disparities explain differences in hypertension prevalence, detection and control in Colombia. J Hypertens. 2016;34(12):2344-52.

19. Laatikainen T, Nissinen A, Kastarinen M, Jula A, Tuomilehto J. Blood Pressure, Sodium Intake, and Hypertension Control: Lessons From the North Karelia Project. Global Heart. 2016;11(2):191-9. 